\title{
Evaluation of the pectoralis major flap for reconstructive head and neck surgery
}

\author{
Astrid L Kruse*, Heinz T Luebbers, Joachim A Obwegeser, Marius Bredell, Klaus W Grätz
}

\begin{abstract}
Purpose: The pectoralis major myocutaneous flap (PMMF) is a commonly used flap in reconstructive head and neck surgery, but in literature, the flap is also associated with a high incidence of complications in addition to its large bulk. The purpose of the study is the evaluation of the reliability and indication of this flap in reconstructive head and neck surgery.

Patients and methods: The records of all patients treated with a PMMF between 1998 and 2009 were systematically reviewed. Data of recipient localization, main indication, and postoperative complications were analyzed.

Results: The male to female ratio was 17:3, with a mean age of 60 years (45-85). Indications in 7 patients were recurrence of a squamous cell carcinoma, in one case an osteoradionecrosis and in 12 cases an untreated squamous cell carcinoma. In 6 male patients (30\%), a complication appeared leading to another surgery.

Conclusion: The PMMF is a flap for huge defects in head and neck reconstructive surgery, in particular when a bulky flap is needed in order to cover the carotid artery or reconstructive surgery, but the complication rate should not be underestimated in particular after radiotherapy.
\end{abstract}

\section{Introduction}

The pectoralis major myocutaneous flap (PMMF) is a commonly used flap for reconstructive head and neck surgery. Ariyan was among the first to use this pedicle flap for head and neck defects [1,2]. Nowadays, free flaps are more common due to improved microsurgical techniques, but in several cases the PMMF still has its advantages, including its proximity to the head and neck, the simplicity of harvesting, and its use as an alternative when microsurgical flap failure occurs. The disadvantages can include a reduced neck mobility and the need to rotate the vascular pedicle of the flap $180^{\circ}$ when using the skin paddle to resurface the neck. Another disadvantage can be the thickness of the flap, which is determined by the amount of subcutaneous fat between the pectoralis muscle and the overlying skin paddle, leading to possible reduced swallowing or speech function. On the other hand, in particular for cases like coverage of a reconstruction plate or coverage of the carotid artery, the bulkiness of PMMF can be an

\footnotetext{
* Correspondence: astridkruse@gmx.ch

Department of Craniomaxillofacial and Oral Surgery, University of Zurich, Switzerland
}

advantage. The PMMF is characterized by a simple procedure and a short time to harvest, but a simultaneous two-team approach is difficult in comparison to the classical forearm or anterolateral thigh flap.

Because of high complication rates in literature [3-13], the aim of the current study is to evaluate and compare the indications and the reliability for this flap in our department.

\section{Patients and methods}

The records of all patients treated with a PMMF between 1998 and 2009 in the Clinic for Craniomaxillofacial and Oral Surgery, at the University Hospital in Zurich were systematically reviewed. The criterion for inclusion was performed PMMF, and for exclusion, inadequate information. Data concerning recipient localization, main indication, and postoperative complications were analyzed.

Major complications were evaluated if revision surgery was necessary and minor ones if conservative wound care alone was required.

(c) 2011 Kruse et al; licensee BioMed Central Ltd. This is an Open Access article distributed under the terms of the Creative Commons 


\section{Surgical technique}

First, the clavicle, xiphoid, ipsilateral sternal border are identified, and then the size and location of the skin paddle being located at the inferior-medial border of the pectoralis major muscle are marked. The vascular axis is drawn on the skin of the chest.

Second, the initial incision is made at the lateral part toward the anterior axillary line down to the pectoralis major muscle.

The maximum amount of muscle should be harvest, because the larger the muscle volume, the safer the flap due to the increased number of myocutaneous perforators (Figure 1). Third, the inferior, medial and lateral incisions are made through the skin, subcutaneous fat and pectoralis fascia down to the chest wall (Figure 2).

The superior incision is made down to the muscle fibres and the skin island is tightened to the muscle with absorbable sutures to protect the skin island during operative handling.

As the muscle is elevated inferiorly to superiorly, the pedicle should be identified by palpation and visualization on the deep surface of the muscle (Figure 3). The pectoralis major muscle derives its blood supply from the pectoral branch of the thoracoacromial artery and lateral thoracic artery. The thoracoacromial artery devides into four branches: pectoral, acromial, clavicular and deltoid. When the muscle fibres are cut along the sternal attachment, special attention should be taken not to cut the internal mammary perforators adjacent to the sternum that supply the deltopectoral flap. During the dissection the vascular bundle should always be seen in order to avoid injury to this bundle.

After dissection the flap off the chest wall, a subcutaneous tunnel is formed under the skin between neck (preserving the perforators to the overlying deltopectoral flap) and the chest and the flap is passed underneath the skin bridge (Figure 4).

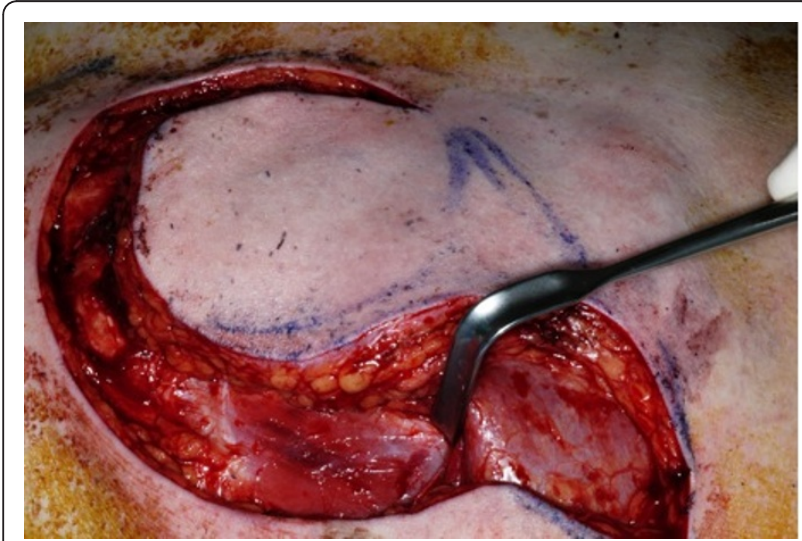

Figure 1 Incision of the flap through the skin, subcutaneous fat and pectoralis fascia down to the chest wall.

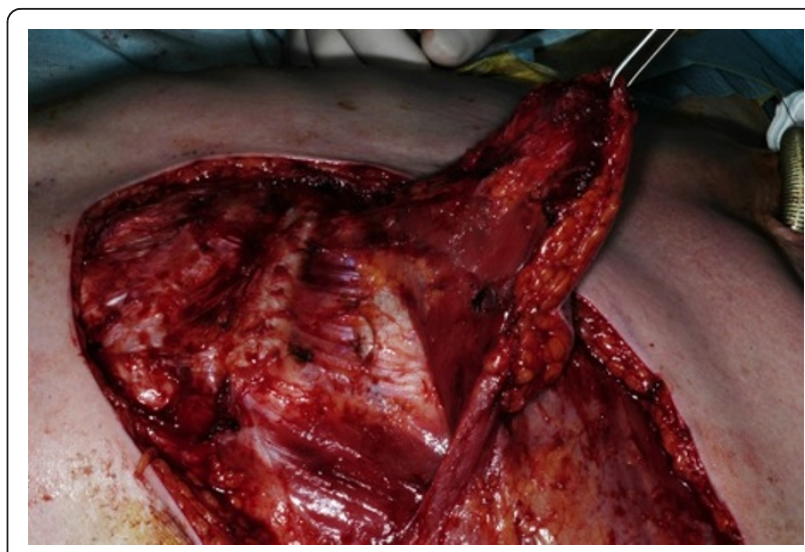

Figure 2 Dissection of the flap off the chest wall.

Magrim et al. recommend in difficult cases, such as in patients with bulky flaps to use sterile liquid vaseline to lubricate the flap and to raise the ipsilateral shoulder in order to facilitate passage and during the procedure, to instill a vasodilator substance (papaverine or lidocaine) over the flap pedicle [14].

\section{Variations}

A myofascial flap can be raised without a skin paddle. In female patients the flap is below the breast.

In order to gain additional length, the skin paddle may be extended as a random-pattern flap beyond the inferior edge of the muscle belly or the clavicular portion of the pectoralis major muscle can be devided above the pedicle by debulking the muscle fibres over the proximal pedicle. Another alternative is to resect the middle third of the clavicle.

In cases of a deltopectoral flap, this flap should be first harvested from its distal part, at least to the medial aspect of the thoracoacromial artery. It is possible to use both, deltopectoral and pectoralis major flap from the same side (Figure 5). The lateral thoracic artery should

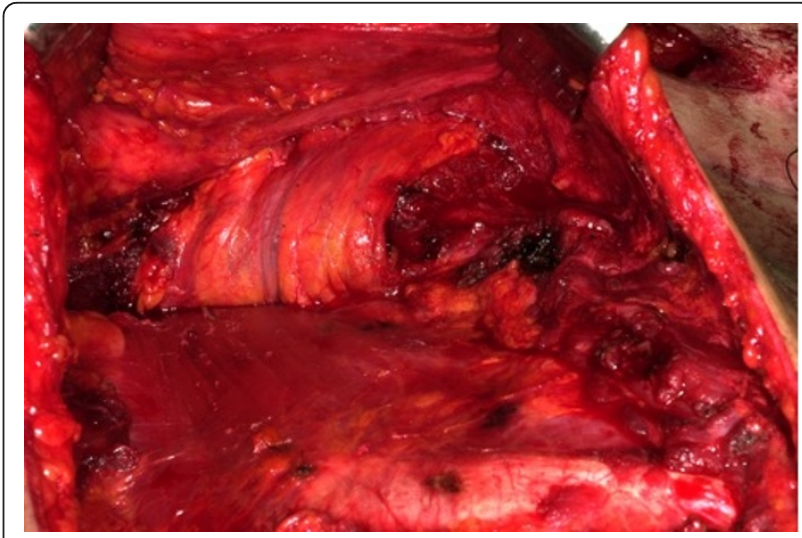

Figure 3 Identification of the pedicel by visualization on the deep surface of the muscle. 


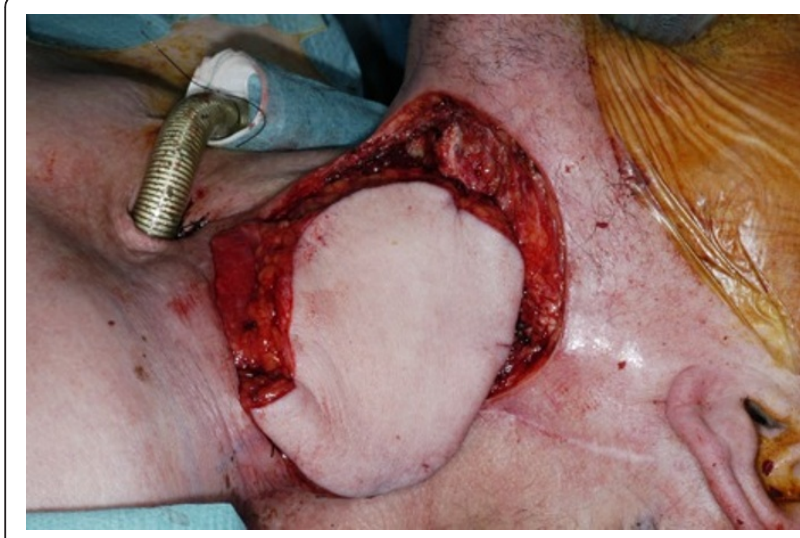

Figure 4 Flap is being passed underneath the skin bridge.

be preserved by dividing the humeral head of the pectoralis major muscle and the lateral border of the pectoralis minor muscle [15].

\section{Results}

Between 1998 and 2009, 20 reconstructions utilizing PMMF were performed by four different surgeons. The patients' male to female ratio was $17: 3$, and the mean age was 60 years (45-85).

Indications in 7 patients were a recurrence of a squamous cell carcinoma, in one case an osteoradionecrosis in order to cover exposed bone, and in 12 cases an untreated squamous cell carcinoma. The primary $\mathrm{T}$ status is listed in Figure 6. The main portion (13/19) was a T4 status.

The defect site distribution is shown in Figure 7. In this study mainly defects of the floor of the mouth or tongue were covered ( $50 \%$ of all sites).

In 6 male patients, a complication appeared, leading to another surgery (Table 1).

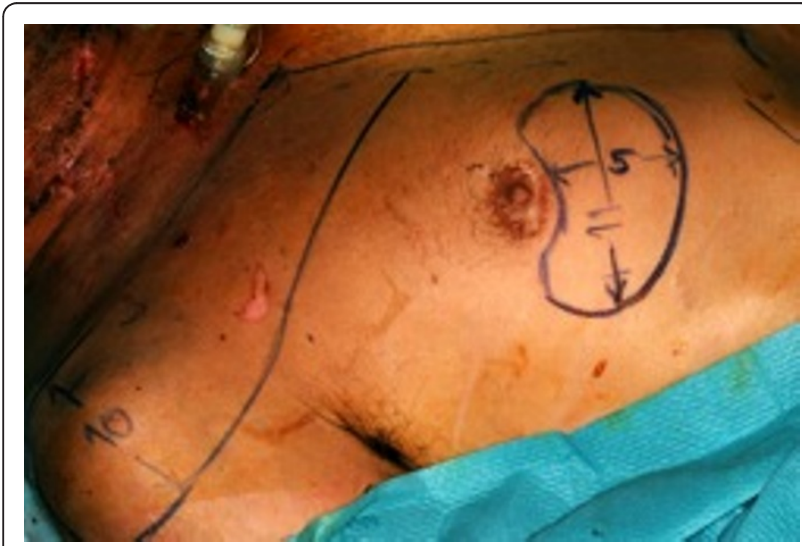

Figure 5 Possibility of harvesting a deltopectoral and pectoralis major flap from the same side.

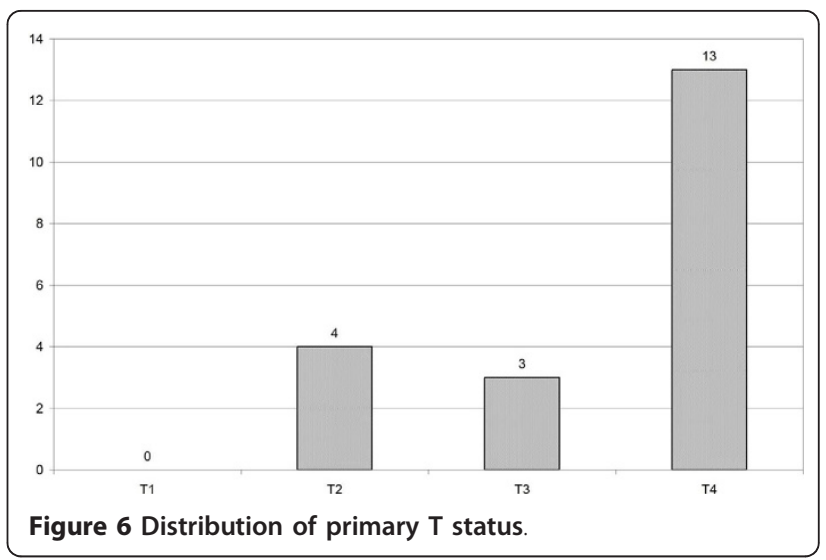

\section{Discussion}

Several modifications have been suggested for multiple purposes. Some authors used only the pure muscle flap without skin, the pectoralis major myofascial flap, in order to reduce the thickness $[16,17]$. However concerning the bulkiness of the flap, a $50 \%$ reduction within 3 months is reported due to atrophy after division of the motor nerves [7].

Others included a segment from the fifth rib in the flap [18-20], but in cases of postoperative radiotherapy, this is not recommended [19]. Of course the flap can be combined with a non-vascularized bone graft, such as a free iliac crest brought out simultaneously [21]. In the current study, none of the patients had a bone graft inserted at the same time.

In females the use of an inframammary incision is recommended for aesthetic reasons [13]: but in the present study the PMMF was performed on only 3 female patients. Chaturvedi et al. described a technique whereby the flap was harvested through the skin paddle incision alone [22].

The double paddle modification as described by Freeman et al. [23] is sometimes an alternative to using

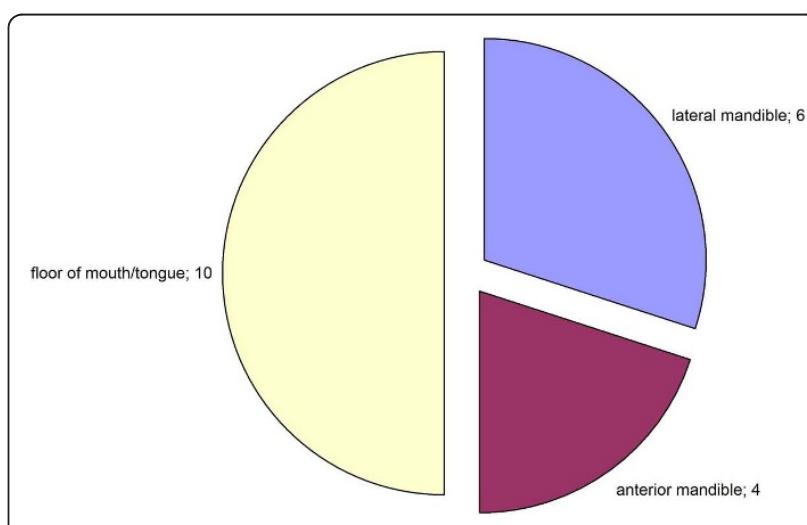

Figure 7 Distribution of defect localizations covered with PMMF. 
Table 1 Reported overall patient group

\begin{tabular}{|c|c|c|c|c|c|}
\hline Gender & Age (years) & Indication & Localization & Radiotherapy & Complications \\
\hline M & 56 & Recurrence & Mandible & Prior & Bleeding (minor) \\
\hline M & 54 & Second oral cancer & Mandible & Prior, contralateral & Partial necrosis \\
\hline M & 64 & Recurrence & Floor of mouth & Prior & - \\
\hline M & 48 & Oral cancer & Floor of mouth & - & Necrosis, flap loss \\
\hline M & 51 & Recurrence & Mandible & Prior & Complete necrosis \\
\hline M & 76 & Recurrence & Mandible & Prior & Hematoma \\
\hline M & 56 & Oral cancer & Floor of mouth & - & - \\
\hline M & 68 & Recurrence & Mandible & Prior & - \\
\hline M & 45 & Oral cancer & Chin & - & - \\
\hline $\mathrm{F}$ & 62 & Recurrence & Mandible & - & - \\
\hline M & 55 & Oral cancer & Floor of mouth & - & - \\
\hline M & 60 & Osteomyelitis, Coverage of exposed bone & Mandible & Prior & Partial necrosis with infection \\
\hline $\mathrm{F}$ & 68 & Oral cancer & Mandible & - & - \\
\hline M & 67 & Oral cancer & Floor of mouth/tongue & - & - \\
\hline M & 58 & Oral cancer & Floor of mouth & - & - \\
\hline $\mathrm{F}$ & 75 & Oral cancer & & - & - \\
\hline M & 53 & Oral cancer & Floor of mouth & - & Hematoma \\
\hline M & 60 & Oral cancer & Floor of mouth & - & - \\
\hline M & 61 & Oral cancer & Floor of mouth & - & - \\
\hline M & 56 & Recurrence & Floor of mouth & Prior & - \\
\hline
\end{tabular}

another flap technique [24]. However, combinations of PMMF and radial forearm flap, fibula flap, and anterolateral thigh flap were successfully performed $[25,26]$.

Concerning closure of the donor-side, most authors performed a primary closure. But in some cases, different techniques have been described like buttons (Figure 8 a) or Ventrofil ${ }^{\circledR}$, a special tension-relief bridging device (Figure 8b) [27].

Several authors have described good results $[28,29]$, but many have also mentioned high complication rates (Table 2).

The current study supports that the harvesting technique is easy, but the postoperative complication possibilities as given in table 3 should not be underestimated [3].

Besides partial or complete necrosis, other complications such as fistula formation, dehiscence, infection, and hematoma are described $[11,30]$. The complication rate seems to be higher than in free flap reconstructions as, e.g., radial forearm flap [30].

Several reasons for complications have been described: while McLean et al [9] reported mainly complications in patients after radiotherapy, El-Marakby [4] mentioned utilization of the PMMF as a salvage procedure, number of comorbidities, oral cavity reconstructions. Zbar et al. found besides the mentioned reasons, complications mainly for covering exposed bone in osteoradionecoris [13].

A higher complication rate seems to be associated with the use of the flap as a salvage procedure and
A

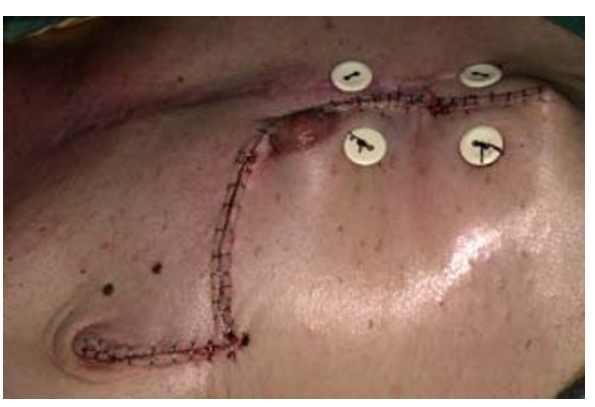

B

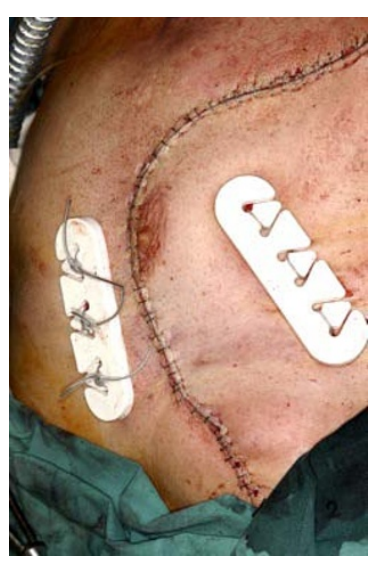

Figure 8 a Closure of the donor side defect with buttons $b$ Closure of the donor side defect with Ventrofil ${ }^{\circledR}$. 
Table 2 Overview of reported complication rates in PMMF

\begin{tabular}{lllc}
\hline Authors & Year of publication & Number of patients/flaps & Reported complication rate \\
\hline McLean et al. [9] & 2010 & $\begin{array}{l}136 \text { patients } \\
139 \text { flaps }\end{array}$ & $13 \%$ \\
\hline Ethier et al. [5] & 2009 & 27 patients & $44.4 \%$ \\
\hline Milenovic et al. [10] & 2006 & 500 patients & $33 \%$ \\
\hline El-Marakby [4] & 2006 & 25 patients & $60 \%$ \\
\hline Vartanian et al. [12] & & 26 flaps & $36.1 \%$ \\
\hline Dedivitis and Guimaraes [3] & 2004 & 371 patients & $41.2 \%$ \\
\hline Liu et al. [8] & 2002 & 17 patients & $35 \%$ \\
\hline Zbar et al. [13] & & 17 flaps & $44 \%$ \\
\hline ljsselstein et al. [6] & 2001 & 229 patients & $53 \%$ \\
\hline Kroll et al. [7] & 1997 & 21 patients & $63 \%$ \\
\hline Shah et al. [11] & 1996 & 24 flaps & $53 \%$
\end{tabular}

the presence of more than one risk factor - e.g. if the patient is a heavy smoker and or the procedure is oral cavity reconstruction [4] - while others reported no significantly higher complication rate associated with smoking, preoperative radiotherapy, or diabetes $[8,12]$. The incidence of flap necrosis is reported in up to $32 \%$ [11,31]. In the current study, in 6 patients out of 20 patients $(30 \%)$, a complication appeared so that a further surgery was necessary. One explanation could be the variations in vascular supply as shown in Table 4.

Therefore Ord recommended incorporating the lateral thoracic artery [19]. Furthermore, larger skin paddles introduce more perforators, and thereby possibly reducing the risk of necrosis.

Another reported point of concern is the problem of hidden recurrence under the flap [32].

Concerning the indication one must be aware on the one hand of the possible arc of rotation of the flap and, on the other hand, of the size of the defect. The latter has an approximate limit in men of $6 \mathrm{~cm}$ squared without the need of a further skin graft for closure: in females this size can be doubled due to greater redundancy of the female breast [33]. In regard to the possible arc of the rotation of the flap, soft tissue defects anterior to the retromolar region and inferior to the ear lobe and commissure of the lips can be reconstructed with relative ease [33].

Concerning the costs of PMMF in comparison to free flap, de Bree et al. have shown that the lower costs of hospital admission (24 days versus 28 days) in the postoperative phase outweighed the higher costs of the surgical procedure (692 min versus $642 \mathrm{~min}$ ) in 40 radial forearm flap patients in comparison to 40 PMMF patients [34].

\section{Conclusion}

The PMMF can be used in particular if a bone graft, a reconstruction plate for huge defects, or a bulky flap is needed for coverage of the carotid artery, but the complication rate should not be underestimated. In general, a microvascular free tissue transfer should be preferred.

Table 3 Known complications associated with pectoralis major myocutaneous flap

\begin{tabular}{lll}
\hline Problem & Suggested solution & References \\
\hline Partial necrosis & Ties instead of electric cautery & Ord [17] \\
\hline & Cutting muscle with Mayo scissors than electrosurgical knife & Carlson [28] \\
\hline Closure of donor-side & Special attention to tension free closure & Wilson et al. [29] \\
\hline Supraclavicular bulge & Excision of muscle over vascular pedicle & Wilson et al. [29] \\
\cline { 2 - 3 } & Turn flap under the clavicle & Phillips et al. [14] \\
\hline Female breast distorsion & Only muscle flap & Zbar et al. [13] \\
\cline { 2 - 3 } & Inframammary approach & Carlson [28] \\
\cline { 2 - 3 } & Lateral incision &
\end{tabular}


Table 4 Blood supply of the pectoralis major according to Tobin [31] and Carlson [28]

\begin{tabular}{lll}
\hline Segment & Vascular supply & Nerve supply \\
\hline Clavicular & Deltoid branch of thoracoacrominal artery & Lateral pectoral nerve \\
\hline Sternocostal & Pectoral branch of thoracoacromial artery & Lateral pectoral and medial pectoral nerve \\
\hline Lateral external & Lateral thoracic artery or/and pectoral branch of thoracoacrominal artery & Medial pectoral nerve \\
\hline
\end{tabular}

Special attention should be given to the skin paddles in order to incorporate enough perforators. Extensive electrocoagulation should be avoided.

\section{Authors' contributions}

AK carried out the evaluation of the patients, TL participated in the analysis of the tables, JO participated in the coordination, MB evaluated the surgical steps, and KG participated in the design and coordination of the study.

\section{Conflicts of interests}

The authors declare that there is no conflict of interest.

Received: 19 July 2010 Accepted: 27 February 2011

Published: 27 February 2011

\section{References}

1. Ariyan S: Further experiences with the pectoralis major myocutaneous flap for the immediate repair of defects from excisions of head and neck cancers. Plast Reconstr Surg 1979, 64:605-612.

2. Ariyan S: The pectoralis major myocutaneous flap. A versatile flap for reconstruction in the head and neck. Plast Reconstr Surg 1979, 63:73-81.

3. Dedivitis RA, Guimaraes AV: Pectoralis major musculocutaneous flap in head and neck cancer reconstruction. World J Surg 2002, 26:67-71.

4. El-Marakby $\mathrm{HH}$ : The reliability of pectoralis major myocutaneous flap in head and neck reconstruction. J Egypt Nat/ Canc Inst 2006, 18:41-50.

5. Ethier $J$, Trites J, Taylor SM: Pectoralis major myofascial flap in head and neck reconstruction: indications and outcomes. J Otolaryngol Head Neck Surg 2009, 38:632-641.

6. IJsselstein CB, Hovius SE, ten Have BL, Wijthoff SJ, Sonneveld GJ, Meeuwis CA Knegt PP: Is the pectoralis myocutaneous flap in intraoral and oropharyngeal reconstruction outdated? Am J Surg 1996, 172:259-262.

7. Kroll SS, Goepfert H, Jones M, Guillamondegui O, Schusterman M: Analysis of complications in 168 pectoralis major myocutaneous flaps used for head and neck reconstruction. Ann Plast Surg 1990, 25:93-97.

8. Liu R, Gullane P, Brown D, Irish J: Pectoralis major myocutaneous pedicled flap in head and neck reconstruction: retrospective review of indications and results in 244 consecutive cases at the Toronto General Hospital. $J$ Otolaryngol 2001, 30:34-40

9. McLean JN, Carlson GW, Losken A: The pectoralis major myocutaneous flap revisited: a reliable technique for head and neck reconstruction. Ann Plast Surg 2010, 64:570-573.

10. Milenovic A, Virag M, Uglesic V, Aljinovic-Ratkovic N: The pectoralis major flap in head and neck reconstruction: first 500 patients. $J$ Craniomaxillofac Surg 2006, 34:340-343.

11. Shah JP, Haribhakti V, Loree TR, Sutaria P: Complications of the pectoralis major myocutaneous flap in head and neck reconstruction. Am J Surg 1990, 160:352-355

12. Vartanian JG, Carvalho AL, Carvalho SM, Mizobe L, Magrin J, Kowalski LP: Pectoralis major and other myofascial/myocutaneous flaps in head and neck cancer reconstruction: experience with 437 cases at a single institution. Head Neck 2004, 26:1018-1023.

13. Zbar RI, Funk GF, McCulloch TM, Graham SM, Hoffman HT: Pectoralis major myofascial flap: a valuable tool in contemporary head and neck reconstruction. Head Neck 1997, 19:412-418.

14. Magrim J, Filho JG: Practical tips for perfomring a pectoralis major flap. In Pearls and pitfalls in head and neck surgery. Edited by: Cerne CR, Dias FL, Dima RA, Myers EN, Wei WI. Basel: Karger; 2008:180-181.

15. Krespi YP, Wurster CF, Sisson GA: A longer muscle pedicle for pectoralis myocutaneous flap. Laryngoscope 1983, 93:1360-1361.
16. Phillips JG, Postlethwaite K, Peckitt N: The pectoralis major muscle flap without skin in intra-oral reconstruction. Br J Oral Maxillofac Surg 1988 26:479-485.

17. Green MF, Gibson JR, Bryson JR, Thomson E: A one-stage correction of mandibular defects using a split sternum pectoralis major osteomusculocutaneous transfer. Br J Plast Surg 1981, 34:11-16.

18. Abe $S$, Ide $Y$, lida $T$, Kaimoto $K$, Nakajima $K$ : Vascular consideration in raising the pectoralis major flap. Bull Tokyo Dent Coll 1997, 38:5-11.

19. Ord RA: The pectoralis major myocutaneous flap in oral and maxillofacial reconstruction: a retrospective analysis of 50 cases. J Oral Maxillofac Surg 1996, 54:1292-1295, discussion 1295-1296.

20. Dieckmann J, Koch A: Primary reconstruction of the mandible with a pedicled muscle and bone transplant-the pectoralis major and rib flap. Fortschr Kiefer Gesichtschir 1994, 39:87-89.

21. Phillips JG, Falconer DT, Postlethwaite K, Peckitt N: Pectoralis major muscle flap with bone graft in intra-oral reconstruction. Br J Oral Maxillofac Surg 1990, 28:160-163.

22. Chaturvedi P, Pathak KA, Pai PS, Chaukar DA, Deshpande MS, D'Cruz AK: A novel technique of raising a pectoralis major myocutaneous flap through the skin paddle incision alone. J Surg Oncol 2004, 86:105-106.

23. Freeman $\mathrm{L}$, Gullane PJ, Rotstein LM: The double paddle pectoralis major myocutaneous flap. J Otolaryngol 1985, 14:237-240.

24. Espinosa MH, Phillip JA, Khatri VP, Amin AK: Double skin island pectoralis major myocutaneous flap with nipple-areola complex preservation: a case report. Head Neck 1992, 14:488-491.

25. Mao C, Yu GY, Peng $X$, Zhang L, Guo CB, Huang MX: Combined free flap and pedicled pectoralis major myocutaneous flap in reconstruction of extensive composite defects in head and neck region: a review of 9 consecutive cases. Hua Xi Kou Qiang Yi Xue Za Zhi 2006, 24:53-56.

26. Chen HC, Demirkan F, Wei FC, Cheng SL, Cheng MH, Chen IH: Free fibula osteoseptocutaneous-pedicled pectoralis major myocutaneous flap combination in reconstruction of extensive composite mandibular defects. Plast Reconstr Surg 1999, 103:839-845

27. Kruse AL, Luebbers HT, Gratz KW, Bredell M: A new method for closure of large donor side defects after raising the pectoralis major flap. Oral Maxillofac Surg 2010.

28. Marx RE, Smith BR: An improved technique for development of the pectoralis major myocutaneous flap. J Oral Maxillofac Surg 1990, 48:1168-1180.

29. Ferri T, Bacchi G, Bacciu A, Oretti G, Bottazzi D: The pectoralis major myocutaneous flap in head and neck reconstructive surgery: 16 years of experience. Acta Biomed Ateneo Parmense 1999, 70:13-17.

30. Schusterman MA, Kroll SS, Weber RS, Byers RM, Guillamondegui O, Goepfert H: Intraoral soft tissue reconstruction after cancer ablation: a comparison of the pectoralis major flap and the free radial forearm flap. Am J Surg 1991, 162:397-399.

31. Mehta S, Sarkar S, Kavarana N, Bhathena H, Mehta A: Complications of the pectoralis major myocutaneous flap in the oral cavity: a prospective evaluation of 220 cases. Plast Reconstr Surg 1996, 98:31-37.

32. Ossoff RH, Wurster CF, Berktold RE, Krespi YP, Sisson GA: Complications after pectoralis major myocutaneous flap reconstruction of head and neck defects. Arch Otolaryngol 1983, 109:812-814.

33. Carlson ER: Pectoralis major myocutaneous flap. Oral Maxillofac Surg Clin North Am 2003, 15:565-575, vi.

34. de Bree R, Reith R, Quak JJ, Uyl-de Groot CA, van Agthoven M, Leemans CR: Free radial forearm flap versus pectoralis major myocutaneous flap reconstruction of oral and oropharyngeal defects: a cost analysis. Clin Otolaryngol 2007, 32:275-282.

doi:10.1186/1758-3284-3-12

Cite this article as: Kruse et al.: Evaluation of the pectoralis major flap for reconstructive head and neck surgery. Head \& Neck Oncology 2011 $3: 12$ 